\title{
Effects of Selected Socio-Demographic Characteristics of Community Health Workers on Performance of Home Visits during Pregnancy: A Cross-Sectional Study in Busia District, Kenya
}

\author{
Ndedda Crispin ${ }^{1}$, Annah Wamae ${ }^{2}$, Meshack Ndirangu ${ }^{3}$, David Wamalwa ${ }^{4}$, \\ Gilbert Wangalwa ${ }^{5}$, Patrick Watako ${ }^{6}$ \& Elijah Mbiti $^{7}$ \\ ${ }^{1}$ Division of Child and Adolescent Health, MOPHS, Kenya \\ ${ }^{2}$ Department of Family Health, MOPHS, Kenya \\ ${ }^{3}$ AMREF, Kenya Country Office \\ ${ }^{4}$ Busia Child Survival Project (BCSP) \\ ${ }^{5}$ Busia Child Survival Project \\ ${ }^{6}$ District Health Management Team Member, Busia District, Kenya \\ ${ }^{7}$ Micronutrient Initiative, Kenya \\ Correspondence: Ndedda O. Crispin, Department of Family Health, Division of Child and Adolescent Health, \\ Ministry of Public Health and Sanitation, Kenya. Tel: 254-722-645-384. E-mail: ndedda@yahoo.com
}

Received: May 13, 2012 Accepted: May 21, 2012 Online Published: July 26, 2012

doi:10.5539/gjhs.v4n5p78 URL: http://dx.doi.org/10.5539/gjhs.v4n5p78

The author had no competing interests

The Study was financed by USAID

\begin{abstract}
Objective: Appropriate performance of home visits facilitates adoption of best practices at home and increased demand for facility based services. Methods: It was a cross-sectional study in which community health workers were observed conducting home visits during pregnancy. Data was collected using a structured questionnaire and the Consultant Quality Index (CQI-2 tool) on record keeping, use of job aids, counselling, client satisfaction and client enablement. Descriptive and inferential statistics were used. Relationships were determined using chi square and odds ratios. Results: The study showed significant relationships of age with good record keeping ( $p$ $=0.0001)$, appropriate use of job aids $(\mathrm{p}=0.0001)$, client satisfaction $(\mathrm{p}=0.018)$ and client enablement $(\mathrm{p}=$ 0.001). Male CHWs were 1.6 times more likely to keep better records than females (OR 1.64 CI (1.02-2.63), while females were more likely to counsel and enable their clients OR 0.42 CI (0.25-0.71) and OR $0.29 \mathrm{CI}$ (012-070) respectively when compared to men. Moreover, higher levels of education were associated with good record keeping OR $0.30 \mathrm{CI}(0.19-0.49), \mathrm{p}=0.0001$; appropriate use of job aids OR $0.30 \mathrm{CI}(0.15-0.61)$ and to appropriately counsel their clients OR 0.34 CI $(0.20-0.58)$ than their lower literacy level counterparts. Experience of CHWs was associated with appropriate use of job aids $(\mathrm{p}=0.049)$; client satisfaction $(\mathrm{p}=$ $0.0001)$ and client enablement $(p=0.032)$. Conclusions: Socio-demographic characteristics of community health workers affect the performance of home visits in various ways. The study also confirmed that CHWs with lower literacy levels satisfy and enable their clients effectively.
\end{abstract}

Keywords: socio-demographic characteristics, performance, home visits, pregnancy, community health workers

\section{Introduction}

A community health Worker (CHW) is any health worker carrying out functions related to health care delivery; trained in some way in the context of the intervention and having no formal professional or paraprofessional certificate, degree or tertiary education (Lewin et al., 2005). Community Health Worker are considered as a third health service delivery work-force (Sein, 2006). The CHWs have evolved with community based healthcare programmes. However, the titles, the profile and the deployment of CHWs have varied enormously across countries, conditioned by their aspirations and economic capacity (Lehmann \& Sanders, 2007). 
Evaluation of community health workers' performance in general, is the focus of much attention at this time, as many countries invest in them as a strategy for the achievement of the millennium development goals (Haines et al., 2007). The effectiveness of Community Health workers (CHWs) has been demonstrated in some studies for example, a CHW programme in India resulted in significant reduction of low birth weight, preterm births and neonatal sepsis (Bang, Baitule, Reddy, \& Deshmukh, 2005). In Cambodia, CHWs were effective in community management of malaria (Yeung, Van Damme, Socheat, White, \& Mills, 2008) and in identification of pneumonia in Uganda (Kallander et al., 2006). CHW's effectiveness is enhanced by the fact that they are local residents, and in principle, always accessible to the villagers. Large centrally managed CHWs' programmes have failed whilst true community based ones work well (Friedman, 2005).

Inadequate performance by CHWs is a widespread problem in many public health fields as demonstrated in malaria control (Morrow, 2009). Studies have also differed on whether socio-demographic factors are important determinants of CHWs' effectiveness (Lehmann \& Sanders 2007). Understanding how the socio-demographic factors influence CHWs' effectiveness in conducting home visits is therefore of paramount importance primarily for the adoption of evidence based maternal, newborn, child health and nutrition best practices and to increase demand for facility based services including skilled birth attendance.

The roles of CHWs include among others: home visits, environmental sanitation, provision of water supply, first aid, treatment of minor and common illness, nutrition counselling, health education and promotion, surveillance, maternal health, family planning, child health, communicable disease control, community development, referrals, record keeping and data collection (Lehmann \& Sanders, 2007).

Community health workers' programmes usually face a myriad of challenges including selection (Jobert, 1985; Ruebush, Weller, \& Klein, 1994), low level or no education, a lack of professional training in health (Brown et al., 2006), the nature of services and workload (Lehmann \& Sanders 2007), inter-relationships between the CHWs, facility health workers and community members (Ballester, 2005) and unclear remuneration/motivation mechanisms (Ballester, 2005) amongst many others. Additionally, the management and supervision of these important staff is challenging for example whether they are accountable to the communities, the health care system or non-Governmental organizations. Their supervisors, ironically, may not have supervisory skills thus compounding the problem. Generally, both men and women are recruited as CHWs at grass-root level although females dominate. Most programmes consist of mature and married CHWs (Lehmann \& Sanders, 2007).

Studies over time have shown that older CHWs are more respected in their communities (Bhattacharyya, Winch, LeBan, \& Tien, 2001). Among some communities such as the Somali, male CHWs find it difficult to pass messages to women (Bentley, 1989). In other communities, resistance from husbands was identified as a key barrier to the participation of women (Brown, Malca, Zumaran, \& Miranda, 2006).

Many but not all CHW programmes require literacy as a pre-requisite (Kaseje, Sempebwa \& Spencer, 1987; Bentley, 1989; Delacollette, Stuyft, \& Molima, 1996; Brown et al., 2006). For example, Kenyan AMREF programmes require seven years of primary education (Chagula \& Tarimo, 1975; Johnson \& Khanna, 2004) while a community self-help health development programme in Sarididi, Kenya did not consider literacy as selection criteria (Kaseje et al., 1987). Some programmes consider ability to read and write and communication skills (Ande, Oladepo, \& Brieger, 2004). Literate CHWs also tend to be younger (Bhattacharyya et al., 2001). However, studies have shown that on one hand, CHWs with higher educational qualifications have opportunities for alternative employment and therefore migrate from one job to another (Brown et al., 2006). On the other hand those with higher education could learn and enhance their skill in the diagnosis of common illness (Bentley, 1989; Kelly et al., 2001; Ande et al., 2004) and thereby deliver better care to the community. Whilst this might be true in some cases, a study in Uganda, found that on the contrary factors like age, sex, education and number of offspring have no effect on CHWs ability to classify Pneumonia and provide treatment accordingly (Kallander et al., 2006).

Few if any studies have investigated the quality of home visits performed by community health workers. This study investigated the effect of selected socio-demographic characteristics on the performance of home visits by CHWs. It is envisioned that findings of this study would inform policy to better implement the community strategy for optimal results.

\section{Methods}

\subsection{Study Area}

The study was undertaken in Funyula and Butula divisions of Busia District, Kenya. Busia District is south of the equator in Western Province and borders Uganda to the West. This is the area where the Division of Child 
and Adolescent Health conducted a pilot study on community based maternal and newborn care through the community strategy in collaboration with the African Medical and Research Foundation (AMREF).

\subsection{Sampling}

The study area had 700 community health workers involved in the implementation of the project spread over seven supervisory areas. Five of these supervisory areas were selected based on CHW population proportion to size. Using lists of CHWs in these areas, 19 were randomly selected from each supervisory area for inclusion in the study. The selected supervisory areas were: Supervisory area 1-Butula Bujumba Bumala; supervisory area 2-Butula Marachi Central; supervisory area 3-Butula Lugulu Elukhari; supervisory area 4-Samia Nambuku Namboboto and supervisory area 5-Samia Nanguba Bujwang'a.Using a cross-sectional design, the study explored the performance of home visits during pregnancy by community health workers involved in community based maternal and newborn care over the study period.

\subsection{Data Collection and Tools}

A supervisory checklist adapted from one used in India (Bang et al., 2005) was used to document home visit observation while the consultant quality instrument (CQI) developed by Howie et al. (2000) ( www.biomedexperts/CQI-2) for client exit interviews was used to determine client satisfaction i.e. the client's perception of the home visit and enablement (the ability of the consultation to result in client behaviour change). Each of the selected community health workers was observed conducting five home visits to pregnant women and the performance of health communication during the consultation was then documented on a structured checklist and an exit interview conducted thereafter by a separate researcher.

\subsection{Variables}

The independent variables were age divided into under 30 years, 30 to 40 years, 40 to 50 years 50 to 60 years and above 60 years sex (male and female) marital status divided into single, married, widow/widower; highest level of education was divided into primary, secondary and above; experience was segmented into 1-2 years, 3-5 years, 6-10 years and above 10 years. The dependent variables were scored on scale record keeping (poor and good), use of job aids (appropriate and inappropriate), counselling skills (appropriate and inappropriate), client satisfaction (low client satisfaction and high client satisfaction) and finally client enablement divided into (client enabled and client not enabled).

\subsection{Data Analysis}

Data was cleaned and entered into SPSS version 18 software for analysis. Descriptive statistics were computed and relationships and significant tests determined using Chi square and Odd Ratios (ORs). The OR is used to assess the possibility of a particular outcome, (performance) if a certain exposure (socio-demographic variable), is present. Further analysis was done using LQAS to compare performance by supervisory area.

\section{Results}

A total of 378 community health worker home visit consultations were observed. Each CHW conducted five home visits staggered over the study period. The CHWs were predominantly female $60 \%$ male $40 \%$. Their ages ranged from 23 to above 60 years. The majority were between 31 and 40 years $(59.3 \%)$ followed by the age group 40 to 50 years $(21.2 \%)$. The under 30 year old made up $15.3 \%$. Only $4.2 \%$ of the CHWs were above 50 years. Most of the community health workers were married (95.8\%).

In regard to the level of education, $67.7 \%$ of CHWs had completed secondary school, $30.2 \%$ primary level of education $30.2 \%$ and $(2.1 \%$ had attained tertiary education with similar percentage having no formal education at all. Distribution of level of education was equal among male and female CHWs. There were disparities in the level of education in the five supervisory areas. In supervisory area four Samia Nambuku Namboboto $84.2 \%$ of the CHWs had secondary and above level of education therefore having the highest proportion of literate CHWs. Supervisory area three had the lowest level $43.7 \%$ of secondary-and-above education.

Results showed that $79.9 \%$ of the CHWs had worked for 3 to 5 years, $10.6 \%$ for 6 to 10 years, $4.2 \%$ had worked for more than 10 years as community health workers. Only $5.1 \%$ had less than 3 years working experience.

\subsection{Effect of Age on Performance}

Table 1 shows that there are strong relationships between age and good record keeping $(\mathrm{p}=0.0001)$, appropriate use of job aids $(p=0.0001)$, client satisfaction $(p=0.018)$ and client enablement $(p=0.001)$. Table 1 shows that there is no relationship between age and gender $(\mathrm{p}=0.129)$. Chi square computations further showed that community health workers aged 40 to 50 years kept best records and also used job aids most appropriately followed by the age group 30 to 40 both parameters. It was further established that the age group 
40 to 50 had the best overall performance of home visits. Those aged 30 to 40 years performed very well in record keeping, use of job aids and client enablement but surprisingly their clients were not satisfied. Those above 60 years kept the worst records, however, this age group enabled their clients more than any other age group. Elderly CHWs were found to have low literacy. It was observed that all age groups had sub-optimal performance in regard to client satisfaction. Client satisfaction appeared to be weakest above 50 years. The young CHWs performed very well in client enablement and also optimally on counselling and appropriate use of job aids. They were a little weak in record keeping and weakest in client satisfaction. There was no relationship of age with appropriate counselling of clients.

Table 1. Effects of age on performance

\begin{tabular}{|c|c|c|c|c|c|c|c|}
\hline & $\begin{array}{c}\text { Under } 30 \\
\text { years }\end{array}$ & $\begin{array}{c}30 \text { to } 40 \\
\text { years }\end{array}$ & $\begin{array}{c}40 \text { to } 50 \\
\text { years }\end{array}$ & $\begin{array}{c}50 \text { to } 60 \\
\text { years }\end{array}$ & $\begin{array}{c}\text { Above } 60 \\
\text { years }\end{array}$ & TOTAL & $\chi^{2}$ \\
\hline \multicolumn{8}{|l|}{ Records } \\
\hline Good record keeping & 32 & 170 & 64 & 4 & 0 & 270 & \\
\hline Poor records & 26 & 54 & 16 & 8 & 4 & 108 & $P=0.0001$ \\
\hline \multicolumn{8}{|l|}{ Use of Job aids } \\
\hline Appropriate use & 46 & 204 & 80 & 8 & 4 & 342 & \\
\hline Inappropriate use & 12 & 20 & 0 & 4 & 0 & 36 & $P=0.0001$ \\
\hline \multicolumn{8}{|l|}{ Counselling } \\
\hline Apprppropriate & 48 & 188 & 58 & 8 & 4 & 306 & \\
\hline Inappropriate & 10 & 36 & 22 & 4 & 0 & 72 & $\mathrm{P}=0.105$ \\
\hline \multicolumn{8}{|l|}{ Client satisfaction } \\
\hline Low satisfaction & 16 & 76 & 34 & 0 & 0 & 126 & \\
\hline High satisfaction & 42 & 148 & 46 & 12 & 4 & 252 & $P=0.018$ \\
\hline \multicolumn{8}{|l|}{ Client enablement } \\
\hline Client not enabled & 56 & 214 & 72 & 8 & 4 & 354 & \\
\hline Client enabled & 2 & 10 & 8 & 4 & 0 & 24 & $P=0.001$ \\
\hline
\end{tabular}

\subsection{Effect of Sex on Performance}

Table 2 shows a significant relation between sex of the CHW and good record keeping $(\mathrm{p}=0.042)$, appropriate counselling $(p=0.001)$, and client enablement $(p=0.004)$. Further tests were undertaken by calculating the Odds Ratio. Table 2 shows that male CHWs were 1.6 times more likely to keep better records than females. On the other hand, female CHWs were $58 \%$ more likely to counsel their clients appropriately than the males OR $0.4295 \%$ CI (0.25-0.71) while the males were $71 \%$ more likelyto enable clients than the females OR $0.2995 \%$ CI (012-070). There was no significant association between gender and appropriate use of job aids and client satisfaction.

Table 2. Effects of sex on performance

\begin{tabular}{lllll}
\hline & Male & Female & Total & $\chi^{2}$ \\
\hline Records & 113 & 157 & 270 & \\
Good record keeping & 33 & 75 & 108 & $\mathbf{P = 0 . 0 4 2}$ \\
Poor record keeping & $1.64(1.02-2.63)$ & Ref & & \\
OR & & & & \\
Use of Job aids & 130 & 212 & 342 & $\mathbf{P = 0 . 4 5 1}$ \\
Appropriate use & 16 & 20 & 36 & \\
Inappropriate use & & & & \\
\hline
\end{tabular}




\begin{tabular}{lllll}
\hline OR & $0.77(0.38-1.53)$ & Ref & & \\
Counselling & & & & \\
Appropriate & 106 & 200 & 306 & $\mathbf{P}=\mathbf{0 . 0 0 1}$ \\
Inappropriate & 40 & 32 & 72 & \\
OR & $0.42(0.25-0.71)$ & Ref & & \\
Client satisfaction & & & 126 & $\mathbf{P = 0 . 2 3 2}$ \\
High satisfaction & 54 & 72 & 252 & \\
Low satisfaction & 92 & 160 & & \\
OR & $1.30(0.84-2.02)$ & Ref & & \\
Client enablement & & & 354 & $\mathbf{P}=\mathbf{0 . 0 0 4}$ \\
Client enabled & 130 & 224 & 24 & \\
Client not enabled & 16 & 8 & & \\
OR & $0.29(012-070)$ & Ref & \\
\hline
\end{tabular}

\subsection{Effects of Level of Education}

Table 3 shows that levels of literacy amongst community health workers is associated with good record keeping, use of job aids and counselling but not satisfaction and enablement. Table 3 further shows that community health workers with higher levels of education were $70 \%$ more likely to keep good records and use job aids more appropriately than less literate ones. They were also $64 \%$ more likely to counsel their clients more appropriately. The results show no association between education level of CHWs and client satisfaction $(\mathrm{p}=0.057)$ and client enablement $(\mathrm{p}=0.726)$.

Table 3. Effects of education level on performance of CHWs

\begin{tabular}{|c|c|c|c|c|}
\hline & Primary & $\begin{array}{c}\text { Secondary and } \\
\text { above }\end{array}$ & Total & $\chi^{2}$ \\
\hline \multicolumn{5}{|l|}{ Records } \\
\hline Good record keeping & 61 & 209 & 270 & \\
\hline Poor record keeping & 53 & 55 & 108 & $P=0.0001$ \\
\hline OR & $0.30(0.19-0.49)$ & Ref & & \\
\hline \multicolumn{5}{|l|}{ Job aids } \\
\hline Appropriate use & 94 & 248 & 342 & \\
\hline Inappropriate use & 20 & 16 & 36 & $P=0.0001$ \\
\hline OR & $0.30(0.15-0.61)$ & Ref & & \\
\hline \multicolumn{5}{|l|}{ Counselling } \\
\hline Appropriate & 78 & 228 & 306 & \\
\hline Inappropriate & 36 & 36 & 72 & $P=0.0001$ \\
\hline OR & $0.34(0.20-0.58)$ & Ref & & \\
\hline \multicolumn{5}{|l|}{ Satisfaction } \\
\hline High satisfaction & 30 & 96 & 126 & $P=0.057$ \\
\hline Low satisfaction & 84 & 168 & 252 & \\
\hline OR & $0.63(0.38-1.02)$ & Ref & & \\
\hline \multicolumn{5}{|l|}{ Enablement } \\
\hline Client enabled & 106 & 248 & 354 & \\
\hline Client not enabled & 8 & 16 & 24 & $P=0.726$ \\
\hline OR & $0.85(0.36-2.06)$ & Ref & & \\
\hline
\end{tabular}




\subsection{Effects of Work Experience}

Chi square tests showed a relationship of experience of CHWs with appropriate use of job aids $(p=0.049)$, client satisfaction $(p=0.0001)$ and client enablement $(p=0.032)$ (Table 4). There was no association of experience with record keeping $(\mathrm{p}=0.398)$ and counselling of clients $(\mathrm{p}=0.929)$. Furthermore, Community Health Workers who had worked for 3 to 5 years had the best records, used job aids most appropriately, and also counselled clients most appropriately. This group also enabled their clients very well. It can be concluded that although this group had a little weakness in client satisfaction, it had the best overall performance of home visits. Highly experienced CHWs satisfied and enabled their clients more than the less experienced counterparts. It was noted that those who had worked for more than ten years performed all the home visit tasks above average (Table 4).

Table 4. Effects of experience on performance

\begin{tabular}{|c|c|c|c|c|c|c|}
\hline & 1 to 2 years & $\begin{array}{l}3 \text { to } 5 \\
\text { years }\end{array}$ & 6 to 10 years & $\begin{array}{c}\text { Over } 10 \\
\text { years }\end{array}$ & Total & $\chi^{2}$ \\
\hline \multicolumn{7}{|l|}{ Records } \\
\hline Good record keeping & 11 & 219 & 28 & 12 & 270 & \\
\hline Poor record keeping & 9 & 83 & 12 & 4 & 108 & $P=0.398$ \\
\hline \multicolumn{7}{|l|}{ Job aids } \\
\hline Appropriate use & 16 & 278 & 36 & 12 & 342 & \\
\hline Inappropriate use & 4 & 24 & 4 & 4 & 36 & $P=0.049$ \\
\hline \multicolumn{7}{|l|}{ Counselling } \\
\hline Appropriate & 16 & 246 & 32 & 12 & 306 & \\
\hline Inappropriate & 4 & 56 & 8 & 4 & 72 & $P=0.929$ \\
\hline \multicolumn{7}{|l|}{ Satisfaction } \\
\hline High satisfaction & 0 & 106 & 8 & 12 & 126 & \\
\hline Low satisfaction & 20 & 196 & 32 & 4 & 252 & $P=0.0001$ \\
\hline \multicolumn{7}{|l|}{ Enablement } \\
\hline Client enabled & 16 & 286 & 36 & 16 & 354 & \\
\hline Client not enabled & 4 & 16 & 4 & 0 & 24 & $P=0.032$ \\
\hline
\end{tabular}

\subsection{Other Significant Findings}

The participating CHWs were drawn from five distinct supervisory areas. A comparative analysis using LQAS showed that cumulatively, some areas had more CHWs having secondary and above level of education than others. Area 3 Butula Lugulu Elukhari had the lowest proportion of high literacy CHWs while area 4 Samia Nambuku Namboboto had the highest proportion of high literacy CHWs. Comparison of performance of home visits in these areas revealed that areas with low literacy level CHWs could counsel appropriately (decision rule 11, score 13), establish high client satisfaction (decision rule 3, score 4) and enable clients (decision rule 16, score 17) just as well as, if not better than those areas with high literacy level CHWs. This finding is significant given that the ultimate goal of health communication is client enablement which is the ability to convince clients adopt evidence based care practices. Low literacy CHWs can achieve this.

\section{Discussion}

This study aimed at establishing how selected socio-demographic characteristics of community health workers affected the delivery of home visits during pregnancy. Results showed that age, sex, level of education, and experience of the community health workers affected the performance of record keeping, use of job aids, counselling on care during pregnancy, client satisfaction and client enablement. There are however, limited similar studies for comparison.

The mature age of the community health workers is related to appropriate counselling and client enablement. The age-group 30 to 40 appeared to be the most appropriate for selection of community health workers in order to 
obtain optimum results. Younger and much older CHWs had sub-optimal performance. This differs from a study in Uganda (Kallander et al., 2006) which found that factors such as age, sex and education had no effect on the CHWs' performance.

Sex of the community health worker was related to good record keeping, counselling and client enablement with female CHWs counselling and enabling their clients better than their male counterparts. This also contrasts with the Uganda study (Kallander et al., 2006) which found no relation of sex with performance. This finding would favour having female community health workers specialize in maternal, newborn, child health and nutrition interventions. The study did not find any relation of marital status with performance.

A higher education level was related to better performance in all parameters except client enablement. This result concurs with a study in Nigeria (Ande, 2004) which observed that literate CHWs could learn and enhance skills and therefore deliver services better. The study however, showed that CHW education level had no influence on enabling clients to adopt best practices. This is an unfortunate scenario given that the ultimate purpose of health communication is behaviour change. A comparison of performance by supervisory areas showed that areas with low literacy CHWs could counsel, satisfy and enable clients effectively therefore agreeing with other studies such as one conducted in Uganda (Kallander et al., 2006). This finding implies that low literacy or illiterate community members should not be discriminated against during selection agreeing with the Sarididi study (Kaseje et al., 1987) in which education was not a selection criterion for CHWs.

Experienced CHWs were found to be most effective at establishing client satisfaction and client enablement both of which are very important for behaviour change and demand creation for services.

\section{Conclusion}

The study established that age, sex, level of education and experience of community health workers are important characteristics to consider in CHW programmes. Community health workers aged 30 to 50 are most appropriate for selection of CHWs partly because this age group is not only still energetic but is apparently socially settled and will likely exhibit lower attrition levels. Female CHWs are best suited to undertake maternal, newborn, child health and nutrition interventions because they counsel and enable clients better than their male counterparts. The fact that areas with low literacy level CHWs could perform home visits effectively by satisfying and enabling their clients implies that $\mathrm{CHW}$ programmes can be implemented in all areas particularly in low income countries with limited access to education. This is despite the fact that literate CHWs grasp concepts quicker.

\section{Authors' Contributions}

NC conceived the study, designed the protocol, analyzed results and drafted the manuscript. AW and MN contributed to the design and in editing the protocol and manuscript DW was the Programme manager of the Busia Child Survival Project GW, an M \& E specialist, took part in the development of study tools EM edited the manuscript PW supervised field data collection.

\section{Acknowledgements and Funding}

Special thanks go to AMREF, Kenya Country Office for supporting publication, the Busia District Health Management Team, staff of the AMREF Busia Child survival project who supported implementation of the home based newborn care component, all participating community health extension workers and community health workers in the Funyula and Butula division community units and all households involved. Individual appreciation is extended to Dr. Santau Migiro, Head, Division of child and adolescent Health, all colleagues at the division of child and adolescent health and Dr Francis Ayuka, Division of Reproductive Health, for assisting with data analysis, write up and editing.

\section{References}

Ande, O., Oladepo, O., \& Brieger, W. R. (2004). Comparison of Knowledge on diarrhoeal disease management between two types of community based distributors in Oyo State Nigeria. Health Education and Research, 19(1), 110-113. http://dx.doi.org/10.1093/her/cyg004

Ballester, G. (2005). Community Health Workers: Essential to Improving Health in Massachusetts. Bureau of Family and Community Health. Boston: Massachusetts Department of Public Health, retrieved from www.mass.gov/dph

Bang, A. T., Baitule, S. B., Reddy, H. M., Deshmukh, M. D., \& Bang, R. A. (2005). Low Birth Weight and Preterm Neonates: can they be managed at home by mother and a trained village health worker? Journal of Perinatology, 25, S72-S81. http://dx.doi.org/10.1038/sj.jp.7211276 
Bentley, C. (1989). Primary Health Care in Northwestern Somalia: A case Study. Social Science Medicine, 28(10), 1019-1030. http://dx.doi.org/10.1016/0277-9536(89)90384-5

Bhattacharyya, K., Winch, P., LeBan, K., \& Tien, M. (2001). Community Health Worker incentives and Disincentives: How they affect motivation, retention, and sustainability, Basic support for Institutionalizing Child Survival Project.

Brown, A., Malca, R., Zumaran, A., \& Miranda, J. J. (2006). On the front line of primary health care: the profile of community health workers in rural Quechua communities in Peru. (p. 11). Retrieved from www.human-resourcehealth.com/content/4/1/11

Chagula, W., \& Tarimo, E. (1975). Meeting basic health needs in Tanzania. In: Newell KW, ed. Health by the people. Geneva: World Health Organization: 145-168.

Delacollette, C., Stuyft, P. V. d., \& Molima, K. (1996). Using Community Health Workers for malaria control: Experience in Zaire. Bulletin of the World Health Organisation, 74(4), 423-430.

Friedman, I. (2005). Community Health Workers and Community caregivers towards unified model of practice: Health Systems Trust.

Haines, A., Sanders, D., Lehmann, U., Rowe, A. K., Lawn, J. E., Jan, S., ... Bhutta, Z. (2007). Achieving child survival goals: potential contribution of community health workers. Lancet, 369, 2121-2131. http://dx.doi.org/10.1016/S0140-6736(07)60325-0

Howie, J. G. R., Heaney, D., Maxwell, M., Walker, J. J., \& Freeman, G. K. (2000). Developing a consultation quality index (CQI) for use in general practice. Fam. Pract., 17, 455-461. http://dx.doi.org/10.1093/fampra/17.6.455

Jobert, B. (1985). Populism and Health Policy: The case of Community Health Volunteers in India. Social Science Medicine, 20(1), 1-28. http://dx.doi.org/10.1016/0277-9536(85)90305-3

Johnson, B. A., \& Khanna, S. K. (2004). Community health workers and home-based care programs for HIV clients. J. Natl. Med. Assoc., 96(4), 496-502.

Kallander, K., Tomson, G., Nsabagasani, X., Sabiiti, J. N., Pariyo, G., \& Peterson, S. (2006). Can community health workers and caretakers recognize pneumonia in Abbatt, F. (2005). Scaling up Health and Education Workers: Community Health Workers. London: DFID Health Systems Resource Centre.

Kaseje, D. C., Sempebwa, E. K., \& Spencer, H. C. (1987a). Community leadership and participation in the Saradidi, Kenya, rural health development programme. Ann. Trop. Med. Parasitol, 81(Suppl. 1), 46-55.

Kelly, J. M., Osamba, B., Garg, R. M., Hamel, M. J., Lewis, J. J., Rowe, S. Y., ... Deming, M. S. (2001). Community health worker performance in the management of multiple childhood illnesses: Siaya District, Kenya, 1997-2001. American Journal of Public Health, 91(10), 1617-24. http://dx.doi.org/10.2105/AJPH. 91.10 .1617

Lehmann, U., \& Sanders, D. (2007). Community health workers — what do we know about them? the state of the evidence on programmes, activities, costs and impact on health outcomes of using community health workers. World Health Organization,

Lewin, S. A., Dick, J., Pond, P., Zwarenstein, M., Aja, G., van Wyk, B., ... Patrick, M. (2005). Lay health workers in primary and community health care. Cochrane Database Syst Rev., (1), CD004015.

Menon, A. (1991). Utilization of village health workers with in a primary health care programme in the Gambia. Journal of Tropical Medicine and Hygiene, 94(4), 268-271.

Morrow, M., Nguyen, Q. A., Caruana, S., Biggs, B. A., Doan, N. H., \& Nong, T. T. (200). Pathways to malaria persistence in remote central Vietnam: a mixed method study of healthcare and the community. BMC Public Health, 9, 85. http://dx.doi.org/10.1186/1471-2458-9-85

Ruebush, T. K., Weller, S. C., \& Klein, R. E. (1994). Qualities of an ideal volunteer community malaria worker: A comparison of the opinions of community residents and national malaria service staff. Social Science \& Medicine, 39(1), 123-131. http://dx.doi.org/10.1016/0277-9536(94)90172-4

Salmen, L. F. (2002). Beneficiary Assessment, an approach described. In E. a. S. S. Development (Ed.), Social Development series Washington D C World Bank. 
Sanders, D. (1992). The state of democratization in primary health care: community participation and the village health worker programme in Zimbabwe. In: Frankel SE, ed. The community health worker. Effective programmes for developing countries. Oxford: Oxford University Press: 178-219.

Sein, U. T. (2006). Health Volunteers: Third Workforce for Health-for-All Movement. Regional Health Forum, $10(1), 38-48$.

Yeung, S., Van Damme, W., Socheat, D., White, N. J., \& Mills, A. (2008). Access to artemisinin combination therapy for malaria in remote areas of Cambodia. Malar J., 7, 96. http://dx.doi.org/10.1186/1475-2875-7-96

\section{Annex IV: CHW Profile Grid}

District ..Location.

Sublocation.

\begin{tabular}{|c|c|c|c|c|c|c|c|c|c|}
\hline $\begin{array}{l}\text { CHW } \\
\text { Code }\end{array}$ & Age & Sex & $\begin{array}{l}\text { Marital } \\
\text { status }\end{array}$ & $\begin{array}{l}\text { Highest level of } \\
\text { Education }\end{array}$ & $\begin{array}{l}\text { Selected } \\
\text { by }\end{array}$ & $\begin{array}{l}\text { Period } \\
\text { served }\end{array}$ & $\begin{array}{l}\text { Household } \\
\text { coverage }\end{array}$ & Supervisor & Supporter \\
\hline & & & & & & & & & \\
\hline & & & & & & & & & \\
\hline & & & & & & & & & \\
\hline & & & & & & & & & \\
\hline & & & & & & & & & \\
\hline & & & & & & & & & \\
\hline & & & & & & & & & \\
\hline & & & & & & & & & \\
\hline & & & & & & & & & \\
\hline & & & & & & & & & \\
\hline & & & & & & & & & \\
\hline & & & & & & & & & \\
\hline & & & & & & & & & \\
\hline & & & & & & & & & \\
\hline & & & & & & & & & \\
\hline & & & & & & & & & \\
\hline
\end{tabular}




\section{Annex V: CHW Knowledge Assessment Tool}

Name:

1. Name four activities of a Community Health Worker in community based mother and newborn care.

2. During pregnancy, name 3 essential care interventions that a pregnant woman should receive from ANC.

3. What are three danger signs for a pregnant woman during pregnancy?

4. Explain three ways the CHW promotes a safe birth.

5. Name three danger signs that can appear in the baby or mother during birth and in the minutes after delivery.

6. What is kangaroo mother care and for whom especially is it used? What? For Whom?

7. Name three essential care interventions in the home to protect the newborn baby?

8. Name three danger signs that can appear in newborns?

9. Name three danger signs that can appear in a woman after giving birth?

Explain what you would do if a 3 day old newborn was very sleepy and difficult to wake up? What could be the problem? 
Annex VI: CHW Case Observation Checklist (allow use of all job aids)

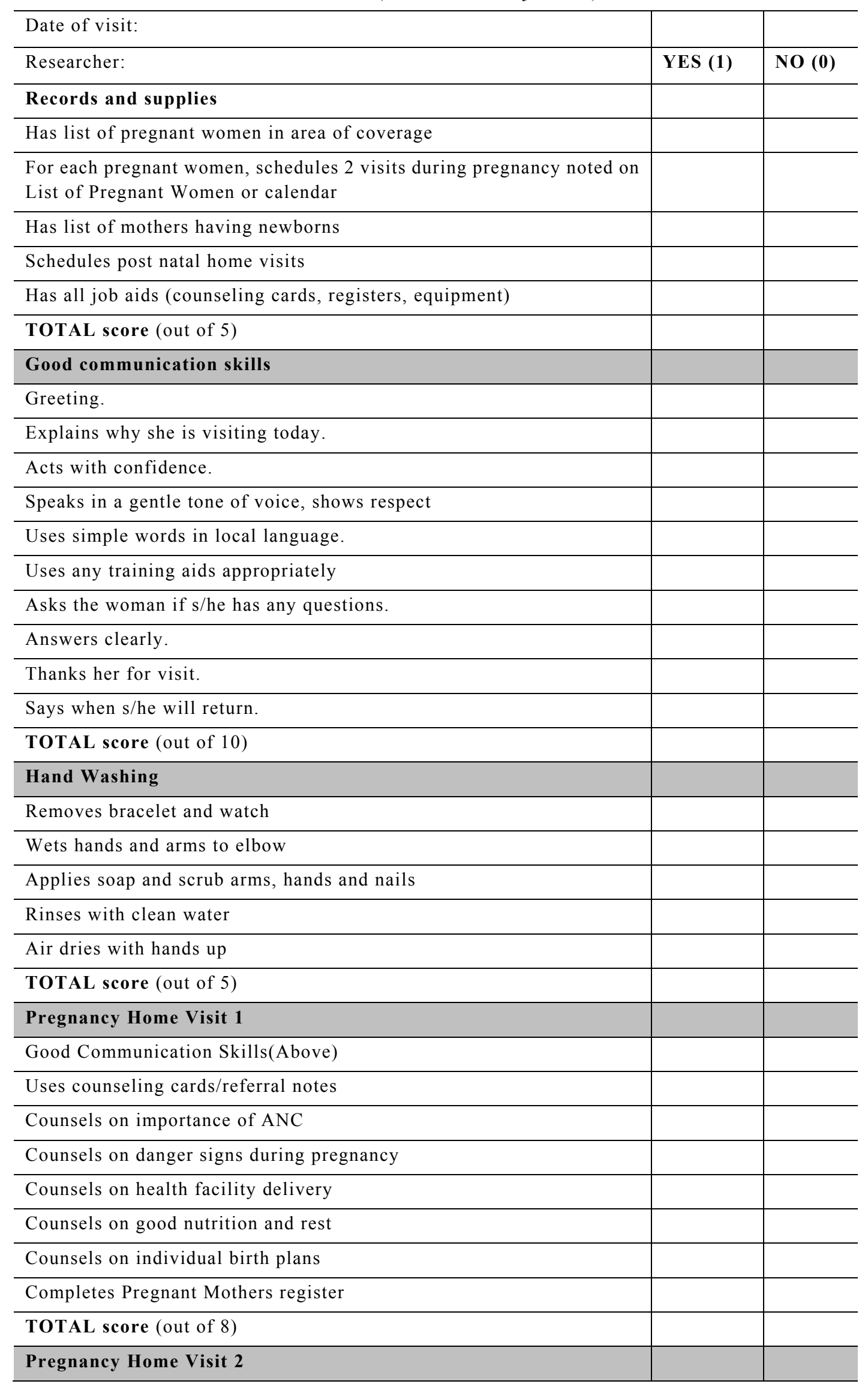




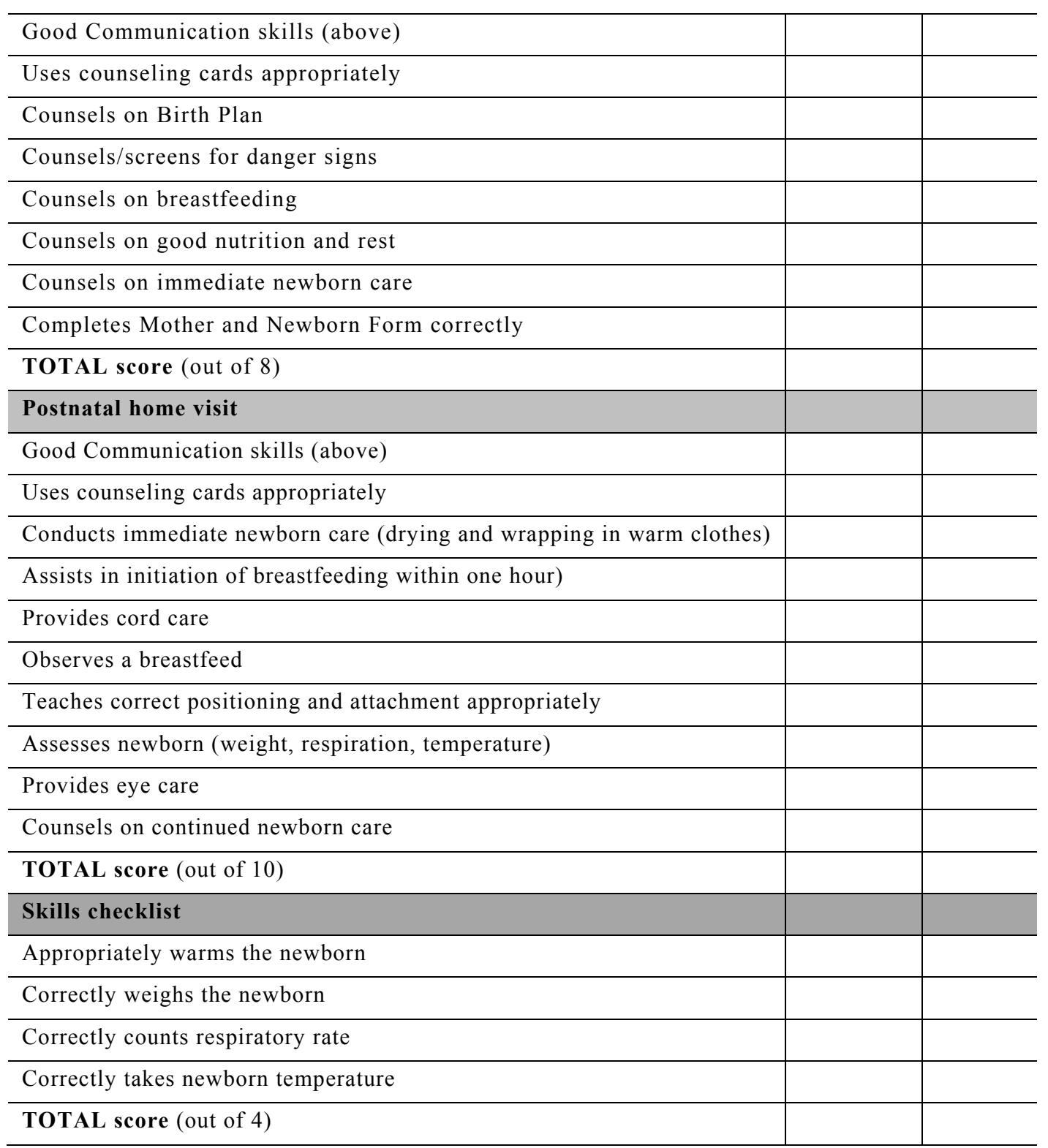

Scores for each parameter will be ranked on an ordinal scale as below average, average and above average performance 


\section{Annex VII: Client Interview Tool-Consultation Quality Index Tool (CQI-2 Tool)}

A: Consultation process measure- CARE (Consultant and Relational Empathy)

Please ask the client and rate the following statements about this CHW home visit consultation

Please tick one box for each statement and answer every statement.

How was the CHW at ...

Poor Fair

1. Making you feel at ease...

(being friendly and warm towards you, treating you with respect; not cold or abrupt)

2. Letting you tell your 'story' ...

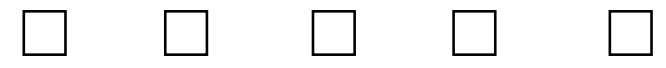

(giving you time to fully express yourself in your own words; not interrupting or diverting you)

3. Really listening ...

(paying close attention to what you were sayings; not Looking/ facing away as you were talking)

4. Being interested in you as a whole person ...

(asking/knowing relevant details about your life, your situation; not treating you passively)

5. Fully understanding your concerns ...

(communicating that s/he had accurately understood your concerns; not overlooking or dismissing anything)

6. Showing care and compassion ...

(seeming genuinely concerned, not being indifferent or 'detached')

7. Being positive ...

(having a positive approach and a positive attitude; not negative about your problems/concerns)

8. Explaining things clearly ...

(fully answering your questions, explaining clearly, giving you adequate information; not being vague)

9. Helping you to take control ...

(exploring with you what you can do to improve your own or child's health; encouraging rather than 'lecturing' you)

10. Making a plan of action with you ...

(discussing the options, involving you in decisions as much as you want to be involved; not ignoring your views)

B: Consultation outcome measure (Patient/client enablement Instrument-PEI)

Please complete these other questions about the home visit consultation by the CHW

As a result this visit by the CHW, do you understand/feel... (please tick one box in each row)

Understand pregnancy/newborn care

Identify danger signs in pregnancy/newborn

Can take appropriate action

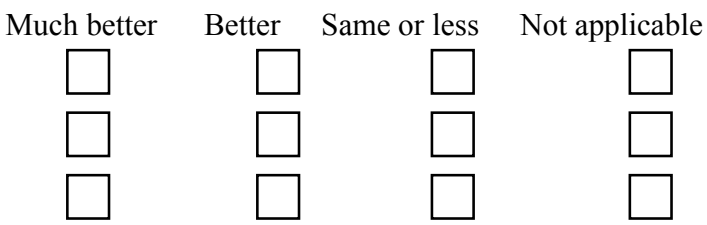

C: Continuity measure

Very well Well Somehow Don't know

1. How well do you know this CHW?

2. What do you say this CHW is

Very good Good Somewhat good No comment 